\title{
Atypical Calcified Ganglioglioma: A Rare Case Report
}

\author{
Seizo Yamashita, Luiz Antonio Resende, Fernanda M. P. Souza, \\ Marco Zanini, Carlos Clayton, André P. Trindade \\ Department of General Surgery, Faculty of Medicine, UNESP, Botucatu, Brazil \\ Email: seizo eid@uol.com.br
}

Received 24 November 2013; revised 24 December 2013; accepted 1 January 2014

Copyright (C) 2014 by authors and Scientific Research Publishing Inc.

This work is licensed under the Creative Commons Attribution International License (CC BY). http://creativecommons.org/licenses/by/4.0/

(c) (i) Open Access

\begin{abstract}
Considered rare tumors, gangliogliomas account for $0.4 \%-0.9 \%$ of intracranial neoplasms. The peak of its incidence occurs between 10 and 20 years of age. These tumors are composed of glial and ganglion cells and they are relatively low-grade neoplasms associated with good prognoses. We report a case of an atypical calcified ganglioglioma in an 18-year-old woman with history of four months of stabbing right-sided parietal headache, paroxysmal. On image studies were noted the presence of thick wall calcification in gangliogliomas. Although rare, this atypical ganglioglioma should be included in the differential diagnosis of lesions occurring in this area of the brain.
\end{abstract}

\section{Keywords}

\section{Gangliogliomas; Brain; Calcification; Atypical}

\section{Case Report}

RCGP, female, 18-year-old, with history of four months of stabbing right-sided parietal headache, paroxysmal, was admitted in our hospital. A temporal tumor was reported since her childhood. At clinical evaluation, the patient was conscious, presenting isochoric and photoreactive pupils with right-sided temporal bone consistency and right ocular proptosis. The normal muscle strength, the sensibility, the reflexes and the cranial pairs were preserved.

The patient was submitted a CT of the brain and the right temporal lobe image revealed a solid expansive process surrounded by a thick calcified capsule.

\section{Discussion}

Gangliogliomas are rare tumors, account for $0.4 \%-0.9 \%$ of intracranial neoplasms and to $1 \%$ - $4 \%$ of all pedi- 
atric neoplasm of CNS. They are relatively low-grade neoplasms associated with good prognoses. The peak of its incidence occurs between 10 and 20 years of age [1]. They can be manifested in newborns with or without neurological alterations and are slightly more common in males. Due its slow growing, the clinical signs and symptoms are usually of long duration such as headaches, focal seizures or, depending of its location, hypothalamic dysfunction.

The ganglioglioma is the most common tumor found in patients with chronic temporal lobe epilepsy. They predominantly affect the cerebral hemispheres, especially the temporal lobe and can also to reach the basal ganglia, cerebellum, brainstem, spinal cord, optic nerve and pineal gland [2] [3]. They can be associated with congenital anomalies such as Down's syndrome and agenesis of the corpus callosum. Rarely hypervascularized, the presence of intratumoral bleeding is not common and, in the majority of the cases, the lesion is avascular [4]. According to the WHO classification, gangliogliomas are graded as Grade I or II and anaplastic gangliogliomas, as Grade III [5] [6] [7]. The anaplastic ganglioglioma is characterized by the presence of hypercellularity areas, vascular proliferation, necrosis and mitotic Figure 1 [8]. On CT, can be manifested as a solid (43\%), cystic (5\%), or a combination of solid-cystic (52\%) mass. Often, the lesions are isodense or hypodense, well-demarcated with a minimal mass effect or surrounding edema. Peripheral location and calcification are common aspects of the gangliogliomas [5]. The tumors can or cannot show enhancement after contrast injection. On images, the aspect is not specific and can be classified by an astrocytoma of lower grade, oligodendroglioma. On MR, they usually are isointense to hypointense in relation to the gray matter on $\mathrm{T} 1$, and mostly hyperintense on $\mathrm{T} 2$.

The malignant degeneration of gangliogliomas is rare (6\%). However, the anaplasia of the glial component has been reported by some authors, and may occurs no differentiation to multiform glioblastoma, that alters significantly the case evolution.

In the current case, the only sign and symptom presented by the patient was a severe right-sided parietal headache during the past four months. Neurological and physical examinations are made and neither changes nor any kind of base pathologies such as hypertension and diabetes were observed. Blood test and biochemical analysis were all normal. The patient was submitted a CT of the brain without intravenous contrast (the patient refused the injection). The image from the right temporal lobe revealed a solid expansive process surrounded by a thick calcified capsule.

The suggested treatment for the patient was the total surgical removal of the tumor. The radiotherapy is indicated for cases of partial removal [2] [3].

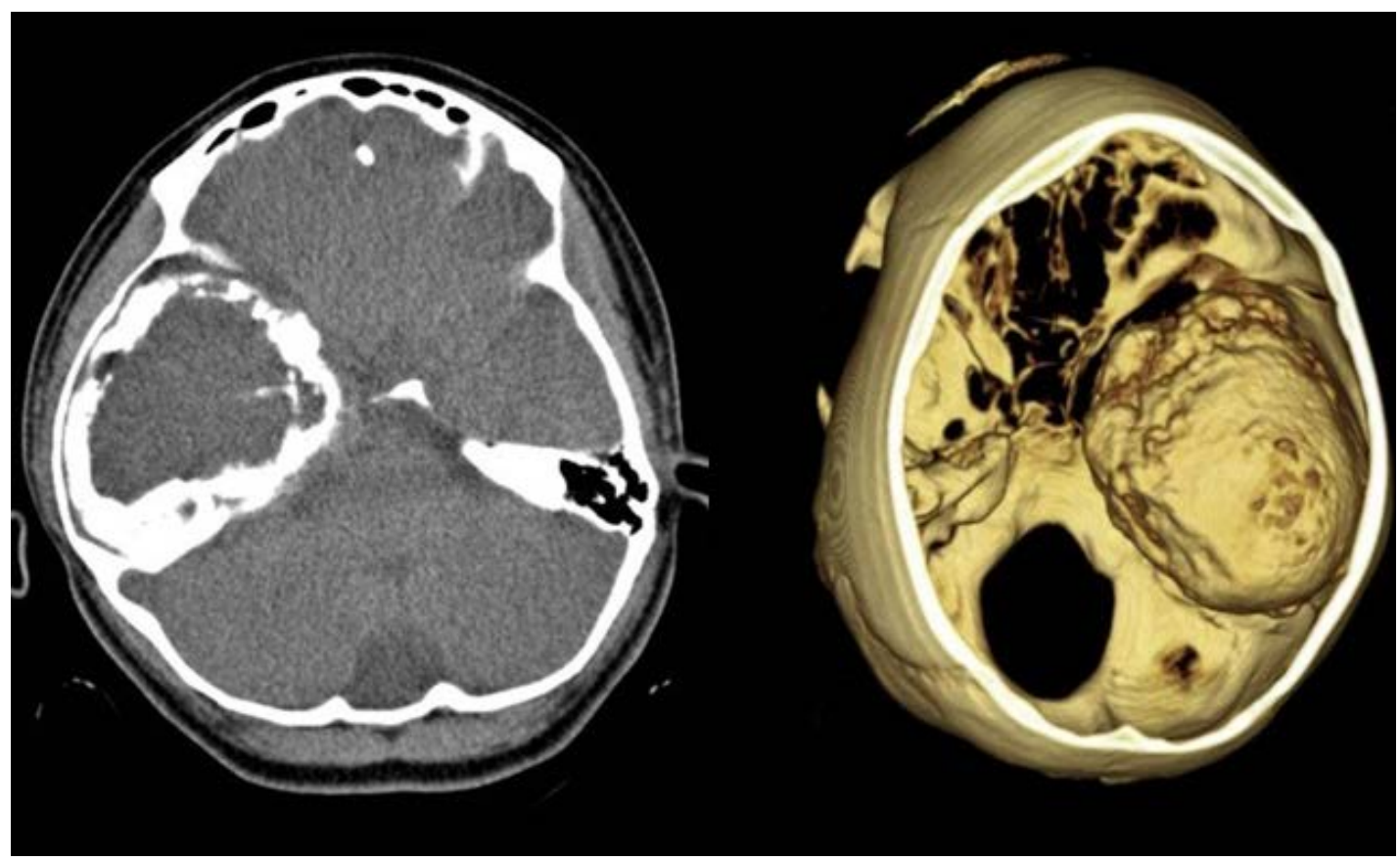

Figure 1. Computed tomography without contrast injection shows a mass lesion surrounded by a thick calcified capsule, in the right temporal lobe. 


\section{Conclusion}

Gangliogliomas is a rare tumor and clearly requires further studies about its origin. Image studies showing the presence of thick wall calcification in gangliogliomas is very rare, and except the current study, no similar case has been found in the radiological literature.

\section{References}

[1] Koeller, K.K. and Henry, J.M. (2001) From the Archives of the AFIP Superficial Gliomas: Radiologic-Pathologic Correlation. RadioGraphics, 21, 1533-1556. http://dx.doi.org/10.1148/radiographics.21.6.g01nv051533

[2] Haddad, S.F., Moore, S.A., Menezes, A.H. and VanGilder, J.C. (1992) Ganglioglioma: 13 Years of the Experience. Neurosurgery, 31, 171-178. http://dx.doi.org/10.1227/00006123-199208000-00001

[3] Miller, D.C., Lang, F.F. and Epstein, F.J. (1993) Central Nervous System Gangliogliomas. Journal of Neurosurgery, 79, 859-866. http://dx.doi.org/10.3171/jns.1993.79.6.0859

[4] Lima, P.L.B., Lima, A.M.B. and Filho, H.R.A. (2006) Ganglioglioma. Comparison with Other Low-Grade Brain Tumors. Arquivos de Neuro-Psiquiatria, 64, 613-618. http://dx.doi.org/10.1590/S0004-282X2006000400018

[5] Chan, A., McAbee, G., Queenan, J. and Manning, A. (2001) Ganglioneurocytoma Mimicking a Malignant Tumor: Case Report with Literature Review of the MRI Appearance of Neurocytomas and Gangliogliomas. Journal of Neuroimaging, 11, 47-50. http://dx.doi.org/10.1111/j.1552-6569.2001.tb00009.x

[6] Kitano, M., Takayama, S., Nagao, T. and Yoshimura, O. (1987) Malignant Ganglioglioma of the Spinal Cord. Acta Pathologica Japonica, 37, 1009-1018.

[7] Russel, D.S. and Rubistein, L.J. (1962) Ganglioglioma: A Case of a Long History and Malignant Evolution. Journal of Neuropathology \& Experimental Neurology, 21, 185-183. http://dx.doi.org/10.1097/00005072-196204000-00002

[8] Wolf, H.K., Müller, M.B., Spänle, M., Zentner, J., Schramm, J. and Wiestler, O.D. (1994) Ganglioglioma: A Detailed Histopathological and Immunohistochemical Analysis of 61 Cases. Acta Neuropathologica, 88, 166-173.

http://dx.doi.org/10.1007/BF00294510 